BIO Web of Conferences 1, 00031 (2011)

DOI: $10.1051 /$ bioconf $/ 20110100031$

(C) Owned by the authors, published by EDP Sciences, 2011

\title{
From inefficient to pop-out visual search in one week
}

\author{
Mark W. Greenlee ${ }^{*} \quad$ Sebastian M. Frank ${ }^{*}$ Eric A. Reavis ${ }^{\dagger}$ Peter U. Tse ${ }^{\dagger}$ \\ (*) Experimental Psychology, University of Regensburg, Germany \\ (†) Department of Brain and Behavior Science, Dartmouth College, Hanover NH, USA \\ E-mail: mark.greenlee@psychologie.uni-regensburg.de,
}

,Eric.A.Reavis@dartmouth.edu,Peter.U.Tse@dartmouth.edu

\begin{abstract}
We investigated changes in brain activity while participants learned to perform a visual conjunction search task over eight successive days. In an eventrelated functional magnetic resonance imaging (fMRI) experiment, subjects searched for a red-green disk amongst many mirror-symmetric green-red distractors. Over sessions, accuracy increased and search-time decreased, indicative of perceptual learning and popout. This behavioral change was correlated with a decrease in neuronal activation in frontal and parietal cortex and an increase in activity in early visual areas during search. Training was specific to the targetdistractor stimuli and did not transfer to other configurations. Our findings suggest that difficult visual search can be learned within a few days and that the trained skill is associated with distinct changes in activation in occipital, parietal and frontal cortex.
\end{abstract}

\section{Introduction}

Most visual activities, whether reading, driving, or playing video games, require rapid detection and identification of learned patterns defined by arbitrary conjunctions of visual features ${ }^{1}$. Initially, such detection is slow and inefficient ${ }^{2}$, but it can become fast and efficient with training ${ }^{3-7}$. To determine how such learning occurs in the brain, we trained observers daily for one week to search for a target that was defined by an arbitrary conjunction of color and location among distractors with the opposite conjunction. During each training session, we measured brain activity with functional magnetic resonance imaging (fMRI).

\section{Methods}

An example of the conjunctive visual search task is given in Fig. 1.

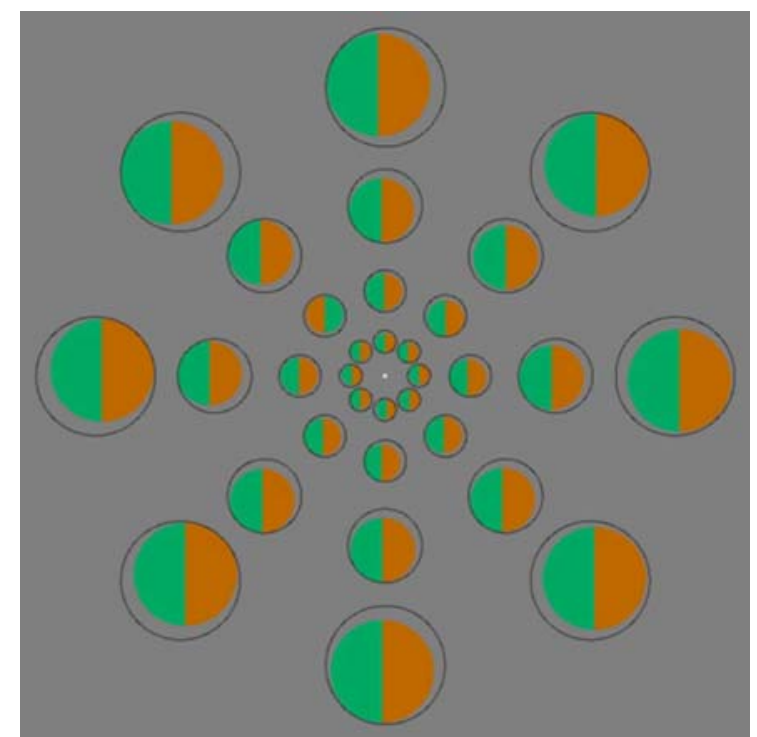

Fig. 1. Example is given of the visual search task used in the experiments. The target is a red-green disk that is randomly presented at one of eight locations in one of the four rings. The task is to determine in which ring the target is located.

Participants performed a five-alternative forced choice task, in which they quickly responded whether the target was present (target absent on $20 \%$ of all trials) and if so, in which ring the target was located (1: inner ring to 4: outer ring). The stimuli were presented for $4 \mathrm{~s}$ and they were spatially jittered within stationary dark-grey circular placeholders over time to avoid perceptual fading. Functional MRI was conducted with a 3-Tesla Siemens scanner (Allegra) using a whole-brain, echo-planer $\mathrm{T} 2 *$-weighted imaging sequence. We identified regions of interest (ROIs) via separate functional localizer scans on each participant for early visual cortex with retinotopic mapping, ${ }^{10}$ lateral occipital cortex ${ }^{11}$, intraparietal sulcus (IPS) ${ }^{12}$ and the frontal/supplementary eye fields ${ }^{13}$. Image

This is an Open Access article distributed under the terms of the Creative Commons Attribution-Noncommercial License 3.0, which permits unrestricted use, distribution, and reproduction in any noncommercial medium, provided the original work is properly cited. 
data were co-registered to high-resolution T1weighted structural scans and analysis performed on the cortical surface with FreeSurfer ${ }^{8,9}$.

\section{Results}

The behavioral results are presented for three participants in Fig. 2. The plots depict reaction time and accuracy over eight fMRI sessions conducted on successive days. As search efficiency increases search times decrease and the hit rate increases to near-perfect performance.

a)

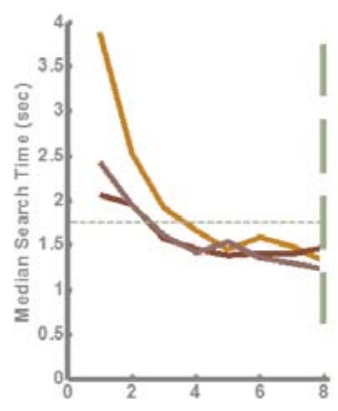

b)

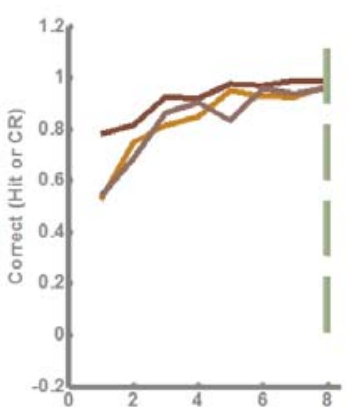

Fig 2. a) Median search times as a function of the successive training day. b) Portion correct (hit rate) as a function of the successive training day. Colors signify different participants $(n=3)$.

The fMRI results are presented for the same participants in Fig. 3a,b. Percent signal change relative to fixation baseline is plotted over the $8 \mathrm{fMRI}$ sessions for primary visual cortex (V1, panel a) and V2 (panel b).

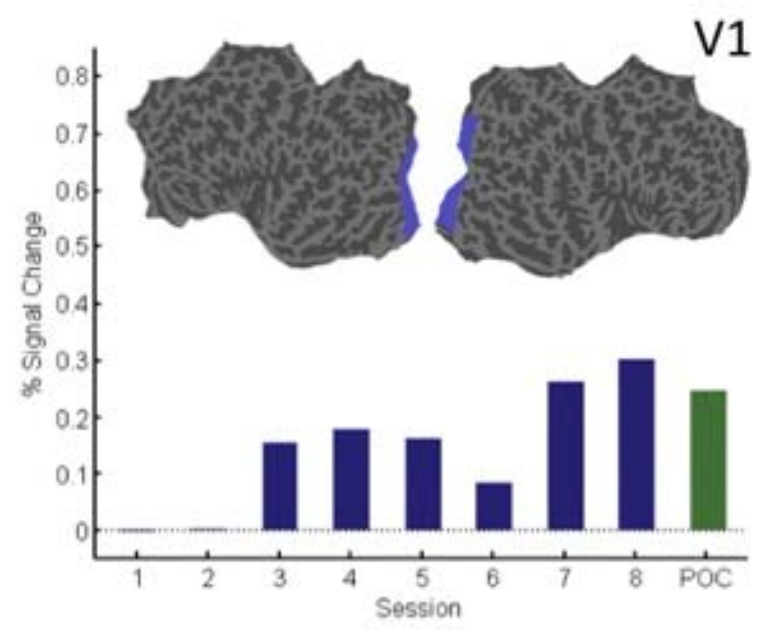

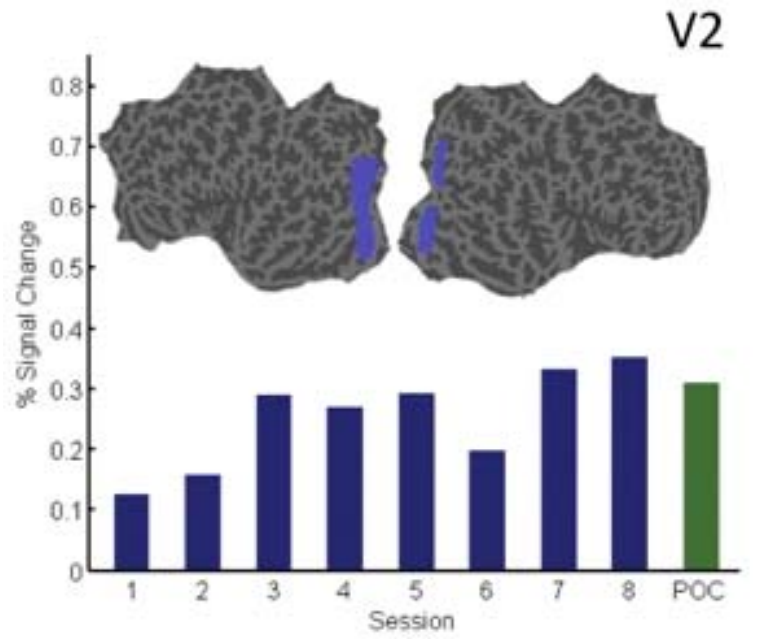

Fig 3. a) Percent BOLD (blood oxygen level dependent) signal change as a function of the successive training day in primary visual cortex (area V1). b) Percent signal changes in area V2 ( $\mathrm{n}=$ 3 ). The highlighted cortical surface portrays the retinotopically defined ROI corresponded to V1 (a) and V2 (b). POC: untrained pop-out control task.

Contrary to early visual areas, the search-related neural activity declined in the intraparietal sulcus (Fig. 4 ), as well as in the frontal and supplementary eye fields (Fig. 5).

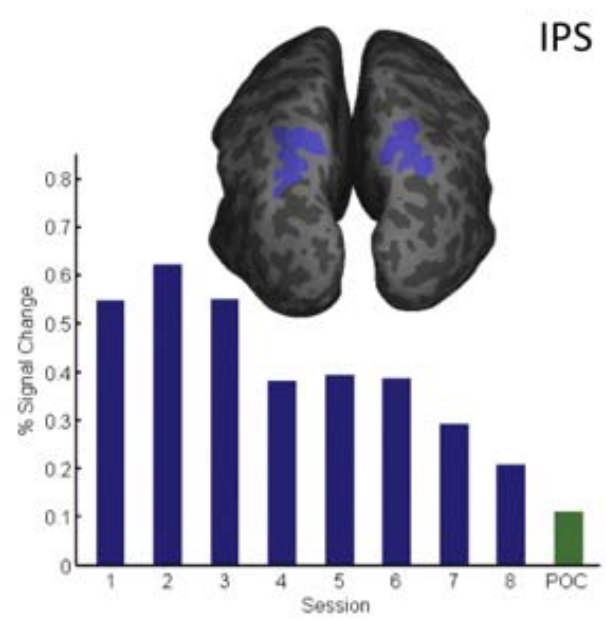

Fig 4. Percent BOLD signal change as a function of the successive training day in posterior parietal cortex (IPS), otherwise as in Fig. 3. 


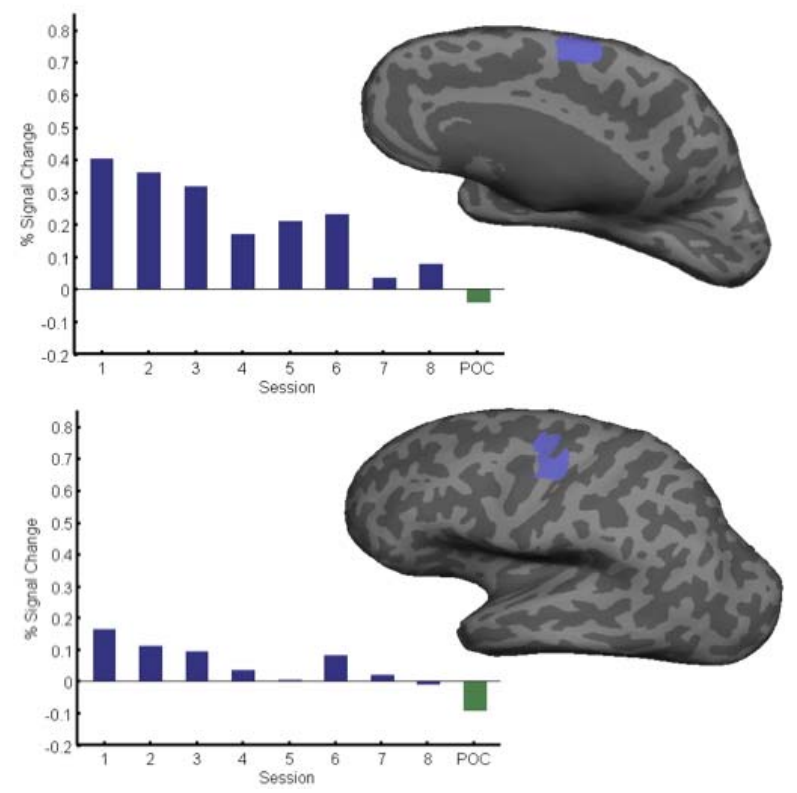

Fig 5. Percent BOLD signal change as a function of the successive training day in supplementary (SEF, upper panel) and frontal eye fields (FEF), otherwise as in Fig. 3.

\section{Discussion}

Our findings illustrate the rapid changes that occur in the adult human brain during perceptual learning and skill acquisition. One week of daily training leads to significant and robust changes in sensitivity, reaction time, and corresponding brain activation. We interpret our results as evidence for a task- and stimulus-specific change in synaptic connectivity in early visual cortex that leads to selective increases in activation of neurons sensitive to learned color configurations. The decrease in activity in the frontoparietal network suggests that target detection becomes effortless, thereby reducing the attentional requirements. The similarity of the amplitude of cortical response in the trained task and the untrained pop-out control task suggests that the neural mechanisms allowing learned search efficiency are similar to those involved in inherent perceptual popout.

\section{References}

[1] Wolfe, J. M., Võ, M. L.-H., Evans, K. K., \& Greene, M. R. (2011). Visual search in scenes involves selective and nonselective pathways Trends in Cognitive Sciences, 15(2), 77-84.
[2] Treisman, A. M., \& Gelade, G. (1980). A featureintegration theory of attention Cognitive psychology, 12(1), 97-136.

[3] Karni, A., \& Sagi, D. (1991). Where practice makes perfect in texture discrimination: evidence for primary visual cortex plasticity Proceedings of the National Academy of Sciences of the United States of America, 88(11), 4966-4970.

[4] Poggio, T., Fahle, M., \& Edelman, S. (1992). Fast perceptual learning in visual hyperacuity Science, 256(5059), 1018-1021.

[5] Heathcote, A., \& Mewhort, D. J. (1993). Representation and selection of relative position. Journal of experimental psychology. Human perception and performance, 19(3), 488-516.

[6] Sireteanu, R., \& Rettenbach, R. (1995). Perceptual learning in visual search: fast, enduring, but nonspecific. Vision Research, 35(14), 2037-2043.

[7] Wang, Q., Cavanagh, P., \& Green, M. (1994). Familiarity and pop-out in visual search Perception and Psychophysics, 56(5), 495-500.

[8] Dale, A. M., Fischl, B., \& Sereno, M. I. (1999). Cortical surface-based analysis. I. Segmentation and surface reconstruction NeuroImage, 9(2), 179194.

[9] Fischl, B., Sereno, M.I., \& Dale, A.M., 1999. Cortical surface-based analysis. II: Inflation, flattening, and a surface-based coordinate system. Neuroimage 9, 195-207.

[10] Engel, S. A., Glover, G. H., \& Wandell, B. A. (1997). Retinotopic organization in human visual cortex and the spatial precision of functional MRI Cerebral cortex, 7(2), 181-192.

[11] Kourtzi, Z., \& Kanwisher, N. (2001). Representation of perceived object shape by the human lateral occipital complex Science, 293(5534), 1506-1509.

[12] Shikata, E., McNamara, A., Sprenger, A., Hamzei, F., Glauche, V., Büchel, C., \& Binkofski, F. (2008). Localization of human intraparietal areas AIP, CIP, and LIP using surface orientation and saccadic eye movement tasks Human Brain Mapping, 29(4), 411421.

[13] Kimmig, H., Greenlee, M. W., Gondan, M., Schira, M., Kassubek, J., \& Mergner, T. (2001). Relationship between saccadic eye movements and cortical activity as measured by fMRI: quantitative and qualitative aspects Experimental brain research, 141(2), 184-194. 